\title{
Using mobile big data to support emergency preparedness and address economically vulnerable communities during the COVID-19 pandemic in Nigeria
}

\author{
Joanne Gilbert $^{1} *$ (D), Olubayo Adekanmbi ${ }^{2}$ and Charlie Harrison ${ }^{1}$ \\ ${ }^{1}$ GSMA, London, United Kingdom \\ ${ }^{2}$ MTN, Lagos, Nigeria \\ *Corresponding author. E-mail: jgilbert@gsma.com
}

Received: 12 January 2021; Revised: 24 May 2021; Accepted: 25 May 2021

Key words: data privacy; mobile big data; mobile insights

\begin{abstract}
With the declaration of the coronavirus disease 2019 (COVID-19) pandemic in Nigeria in 2020, the Nigeria Governors' Forum (NGF) instigated a collaboration with MTN Nigeria to develop data-driven insights, using mobile big data (MBD) and other data sources, to shape the planning and response to the pandemic. First, a model was developed to predict the worst-case scenario for infections in each state. This was used to support state-level health committees to make local resource planning decisions. Next, as containment interventions resulted in subsistence/daily paid workers losing their income and ability to buy essential food supplies, NGF and MTN agreed a second phase of activity, to develop insights to understand the population clusters at greatest socioeconomic risk from the impact of the pandemic. This insight was used to promote available financial relief to the economically vulnerable population clusters in Lagos state via the HelpNow crowdfunding initiative. This article discusses how anonymized and aggregated mobile network data (MBD), combined with other data sources, were used to create valuable insights and inform the government, and private business, response to the pandemic in Nigeria. Finally, we discuss lessons learnt. Firstly, how a collaboration with, and support from, the regulator enabled MTN to deliver critical insights at a national scale. Secondly, how the Nigeria Data Protection Regulation and the GSMA COVID-19 Privacy Guidelines provided an initial framework to open the discussion and define the approach. Thirdly, why stakeholder management is critical to the understanding, and application, of insights. Fourthly, how existing relationships ease new project collaborations. Finally, how MTN is developing future preparedness by creating a team that is focused on developing data-driven insights for social good.
\end{abstract}

\section{Policy Significance Statement}

MTN Nigeria had prior experience of working with call detail records data to create insights, but on a much smaller scale. A key factor in the success, and significant increase in scale, for this project was the support and guidance from the regulatory body, the Nigerian Communications Commission (NCC). Following the government request for insight, MTN began to discuss the approach, and particularly the approach to data privacy, with NCC. The GSMA coronavirus disease 2019 (COVID-19) Data Privacy Guidelines and the Nigeria Data Protection Regulation were used as a starting point for discussion, and NCC supported the entire process as everyone responded rapidly to address the threat posed by COVID-19. This enabled MTN to deliver insights at a national level (population 195 million), using data from a 3-4-month time period to support the COVID-19 response. 


\section{Introduction}

Nigeria was among the first countries in Sub-Saharan Africa to identify and record coronavirus disease 2019 (COVID-19) cases (World Bank, 2020); and one of the worst affected countries in Africa. As of August 2020, the number of cases in the West African country was the third highest on the continent (Omondi, 2020).

In response to the outbreak, strict measures to contain the spread of the virus were implemented including a presidential order for a lockdown over a 2-week period nationwide.

Containment interventions have had a significant impact on the economy. As businesses, schools, and government departments practically shut down, many private organizations laid-off workers, and the remaining staff saw salaries reduced or not paid at all. Essential food items doubled in price due to panic buying, and the cost of public transportation increased as passenger numbers were reduced to meet social distancing mandates (Ayoade, 2020). The economic downturn has been compounded by the collapse in oil prices, significantly reducing government revenues and resulting in further profound implications for the Nigerian economy (Deloitte, 2020).

Before the crisis, $45.6 \%$ of Nigerians were living below the national poverty line, and the unemployment rate stood at $23.1 \%$. The International Growth Center estimated that, at the end of May 2020, containment measures in the region had pushed an additional $9.1 \%$ of the population into extreme poverty (GSMA Intelligence, 2020).

At the start of the pandemic, the priority focus was to ensure the appropriate distribution of medical supplies across the country. Soon after, alleviating the economic impacts of the COVID-19 crisis became vital for the most vulnerable members of the population of Nigeria.

This article describes a collaboration between MTN, Nigeria's largest mobile network operator, and the Nigeria Governors' Forum (NGF), which first developed a model to support medical resource planning across the country, and later identified those in the population at greatest social and economic risk, informing mitigation strategies with the use of mobile big data (MBD).

\section{The Aim of the Collaboration}

A collaboration between MTN Nigeria and the NGF Secretariat began in April 2020 (Chirkpi, 2020) to profile the vulnerability of Nigeria's 36 states to the spread of COVID-19, based on parameters such as population age and density, travel history, and location. The initial focus was on resource allocation including the allocation of critical medical staff, medical supplies, and personal protective equipment to states based on the predicted spread of the disease.

Later, the NGF agreed to the extension of the activity, to develop a vulnerability model and enabled a data-driven approach to mitigating the impact of COVID-19 in the country. The NGF identified that Nigeria's 36 states were best positioned to administer palliatives to mitigate the impact of the crisis, including the distribution of food and essential materials to households to help them cope with the expected loss of income and livelihoods (Essien, 2020).

MTN contributed pro bono as part of its COVID-19 intervention activity, under the broader name Y'ello Hope Package, deployed to support national efforts at containing the spread of the COVID-19 virus, mitigate the pandemic's social and economic impact, and keep customers connected to their loved ones, critical resources, and support (Biodun, 2020; MTN Online, 2021).

\section{Phase 1: Medical Resource Planning}

A three-step approach was taken to plan for the resource allocation. These steps were followed for each state. The first step was to assess the vulnerability based on age profile. Next, a prediction model was used to estimate the disease transmission risk and predict the number of cases that would occur. MTN used its in-house prediction modeling platform, powered by SAS and open-source analytics tools. Finally, using World Health Organization guidelines, an estimate of required resource was calculated. 


\subsection{Age based vulnerability assessment}

Initial global indicators were showing that some demographics were more at risk of a serious or fatal reaction to the COVID-19 infection (Dowd et al., 2020; Onder, et al., 2020), so the team built an age profile for the population of each region by combining data from the MTN network with third-party data from an open-source, public data repository for geospatial reference datasets.

MTN generated anonymized and aggregated location data from their network that was used to derive population volume estimates for each state. This was extrapolated using public data describing market share, mobile user numbers and market distribution by state, to represent the whole population. Country level market share data are available from the Nigerian industry regulator (Nigerian Communications Commission, 2020). For state-level market share, data are available from the Nigerian National Bureau of Statistics (Nigerianstat.gov.ng, 2020).

Age and gender data from GeoPoDe (2020), an open-source, public data repository for geospatial reference datasets funded through the Bill and Melinda Gates Foundation, was overlaid to develop an age profile for each state.

\subsection{Predicted number of cases in each region}

Through the application of international roaming data from MTN's mobile network, population density data, and administrative boundary data, the team predicted the worst-case scenario case numbers for the epidemic in each state using a compartmentalized epidemiological model.

Mobile networks need to record details for billing purposes when a subscriber travels outside of the country and roams onto a foreign mobile network. Roaming data from MTN subscribers was used to develop an international travel profile by state. This was achieved using anonymous and aggregated call detail records (CDR) data to identify the Nigerian states with subscribers that had traveled to countries with reported cases of SARS-CoV-2. At the time these were China, South Korea, Italy, United Kingdom, and United States. The total market share of all operators was used to extrapolate the Nigeria traveler's universe based on the Nigerian Communications Commission (NCC) market share report (Nigerian Communications Commission, 2020).

Next, data on age distribution, population density, and state contiguity (the proximity of a state to other states where COVID-19 cases had been identified) were layered to create a risk model for each state. At this stage, the model included assumptions about the risk of disease transmission. For example, it was assumed that high volumes of population movement between states resulted in a greater risk of exposure and transmission. Similarly, higher transmission was associated with higher-density populations. Linked to these was a focus on densely populated interstate border towns and cities, with a higher propensity for border crossing, and therefore higher risk of transmission. Conversely, some towns and cities are more isolated, due to poor infrastructure or situation relative to natural geographical barriers, and the assumption was that these populations are at a lower risk of exposure and transmission. Data on population density and the locations of over 500,000 key infrastructure points-of-interest, including settlements, hospitals, schools, major roads, and banks, was collected from GRID3 (Welcome - GRID3, 2020). Data on population movements were extracted from MTN's mobile data based on the locations of subscriber identification modules (SIMs), and these were calibrated using population data from Grid 3 and GeoPoDe. These datasets were combined and used to assess the level of contiguity between neighboring states, as a measure of the degree of travel between them. Finally, the Nigeria Centre for Disease Control provided the epidemiological metrics. The number of new cases per day, and the transmission rate (daily changes by state), were used to build a disease transmission risk and case prediction model based on Kucharski et al.'s (2020) SEIR model, a model that splits the population into categories - susceptible, exposed, infected, and removed (Figure 1).

\subsection{Worst-case predictions and medical resource mapping}

The results of this modeling were used to perform a needs-based assessment. The predicted worst-case scenario infection numbers in each state were mapped against the World Health Organization medical 


\section{COVID19 Risk Modeling}

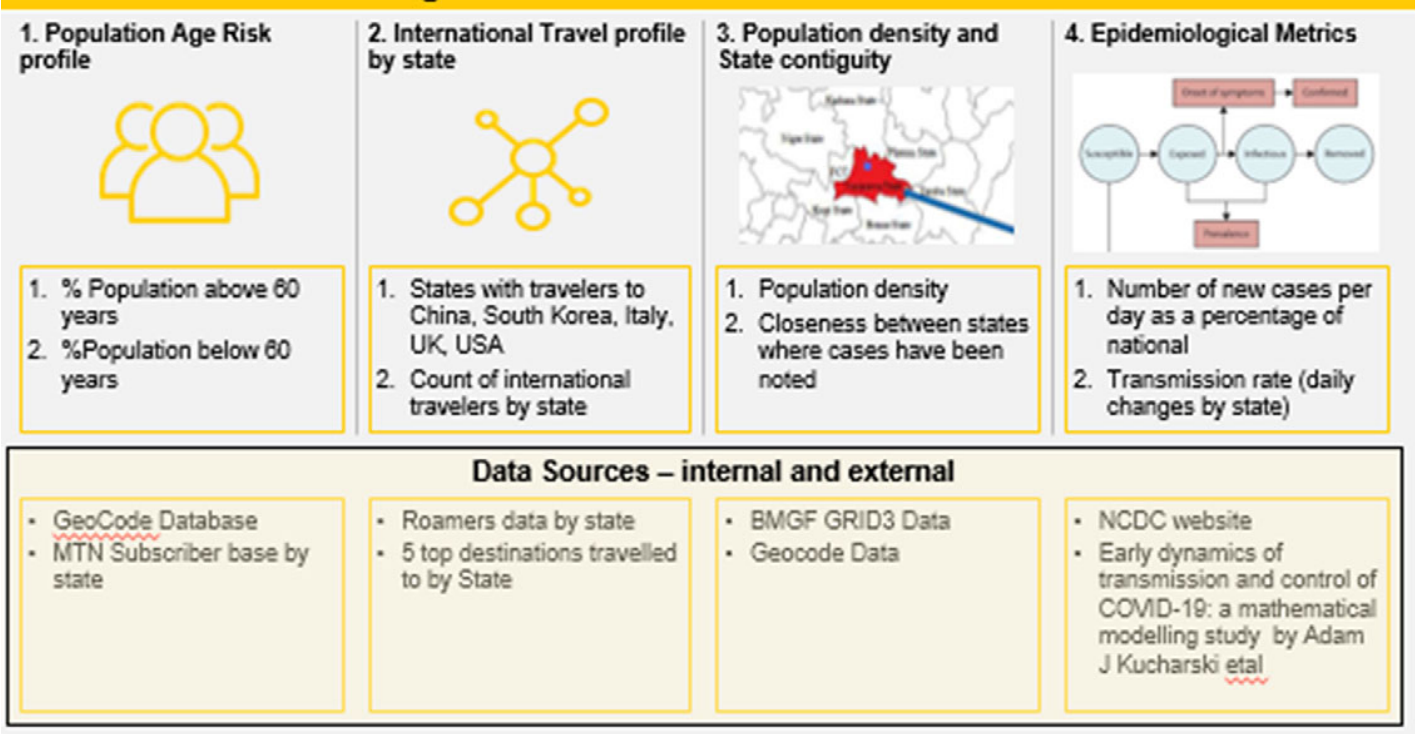

Figure 1. Summary example of MTN Coronavirus Disease 2019 risk modeling.

resource recommendations. The result was used to inform state-level resource planning. A lack of reporting of COVID-19 cases, reports of self-treatment, and testing capacity limitations (Chitungo et al., 2020), however, limited the ability for the team to later contrast the predicted worst-case scenario infection numbers with the actual figures for the period of time the modeling applied to.

\section{Phase 2: Identifying Economically Vulnerable Population Clusters}

Following the first phase, the NGF agreed to an extension of the activity with the aim of identifying clusters of the population at greatest social and economic risk, following virus containment interventions, and informing mitigation strategies.

For this model, MTN provided anonymized and aggregated mobile account top-up and mobile money transaction volumes. Insights derived from these data, based on the value and volume of transactions, can be used as a proxy for economic activity in each region, where lower value and lower volume transactions indicate economically vulnerable areas, and a sudden reduction in transaction value and volume could indicate a downturn in activity.

The vulnerability score was aggregated at cluster level, with a cross industry database of sociodemographic segmentation groupings, incorporating data from, Lagos State; World Bank Data on the poorest households; LASRRA Data on aged Lagosians; Lagos State Residents for those living with disabilities; Bank of Industry Data on Market Women.

However, multiple SIM ownership in Nigeria has implications for the use of mobile account and mobile money transaction data as a proxy economic indicator. Many Nigerians own multiple SIM cards from different operators, and the use of dual-SIM handsets is widespread. Therefore, the account top-up value and mobile money transaction volume data may not reflect the true levels of activity as consumers may have different spending profiles with different operators.

To mitigate this multi-SIM effect, MTN used open data to enable the data analysts to use the location profile of the SIM to estimate how geodemographic factors may be a proxy for more accurate profiling. The mobile data were validated using third-party economic indicators from GeoPoDe and GRID3. Indicators of population density, age distribution, contiguity, and access to community support enabled 
the team to develop regional socioeconomic profiles and use the dynamic, responsive nature of the mobile data to monitor the ongoing situation.

\subsection{Results and discussion}

The COVID-19 risk modeling supported two key outcomes. The first was a worst-case scenario prediction model of SARS-CoV-2 incidence across each of the 36 Nigerian states. These data were made available at state-level to support medical resource planning and allocation. The second was the identification of socioeconomically vulnerable population clusters to inform state intervention decisions.

Many workers in Nigeria live a hand-to-mouth existence. The movement restrictions imposed to contain the epidemic had a direct and immediate impact on the ability of these workers to earn a living wage and buy essential food supplies. In many places, people started taking care of their neighbors. Encouraged by religious groups and nonprofit organizations, the wealthier communities pulled resources together and found organizations that could cook food for the economically vulnerable people in their community (Akinwotu, 2020; Bayagbon, 2020; Nwachukwu, 2020; Partners, 2020).

However, many economically vulnerable groups are isolated from this type of support, situated in locations where accommodation is cheaper, such as informal/slum housing, in places less accessible due to poor infrastructure, and in areas away from the main roads, where much commercial activity takes place in Nigeria. The second phase of activity focused on combining insights to identify where these lowincome and unsupported populations were clustered.

\subsection{National needs analysis and resource requirement dashboard}

At the start of the pandemic, each state set up a health committee that reported to a national center. A member of the NGF was responsible for medical support at the national center. MTN presented the National Needs Analysis and Resource Requirement Dashboard centrally and from there the data were cascaded to all of the commissioner of health across the 36 states (Figures 2-4).

\subsection{Vulnerability population cluster insights}

Communicating the insights from Phase 2 on vulnerable population clusters was more complex as the governance structure for social welfare interventions in Nigeria differs by state. Each state has a social committee, so in the absence of a central coordination point, MTN worked directly with the heads of the social committees, which may have been a governor or a commissioner in each state. MTN engaged the state on a regular basis to provide analytics support on the data.

At these meetings MTN gave an overview of the dashboard with guidance on how to use the data. Separately, they also provided a list of coordinates within each state, in spreadsheet format, indicating the areas at greatest socioeconomic vulnerability. MTN engaged in capacity building efforts, demonstrating how the coordinates could be utilized in a geographic information system application to highlight the locations. At the meetings, the team observed that the state representatives were able to anecdotally validate the findings through their local geographical knowledge (Figures 5 and 6).

\section{Phase 3: Private Sector Intervention}

Inspired by the way that local communities had supported their neighbors, a coalition of partners worked together to formalize what had been happening in neighborhoods across the country. Softcom, a Nigerian technology company, built a crowdfunding platform supported by MTN, Lagos State Government, Deloitte, Ernst \& Young, Eyowo, SANEF, GTBank, Providus Bank, Future Africa, Qrios, Bank of Industry, John Ashley, Wilddreams and Banwo \& Ighodalo. The initiative, which they named HelpNow (Homepage HelpNow, n.d.), was designed to collect and disperse donations to the most vulnerable in Lagos state. Phase 3 was a private sector intervention initiated by Softcom, and was not part of the scope with the NGF, however, this activity was carried out in conjunction with the Lagos State government, of which the Governor is a member of the NGF. The role of each stakeholder is captured in Table 1. 

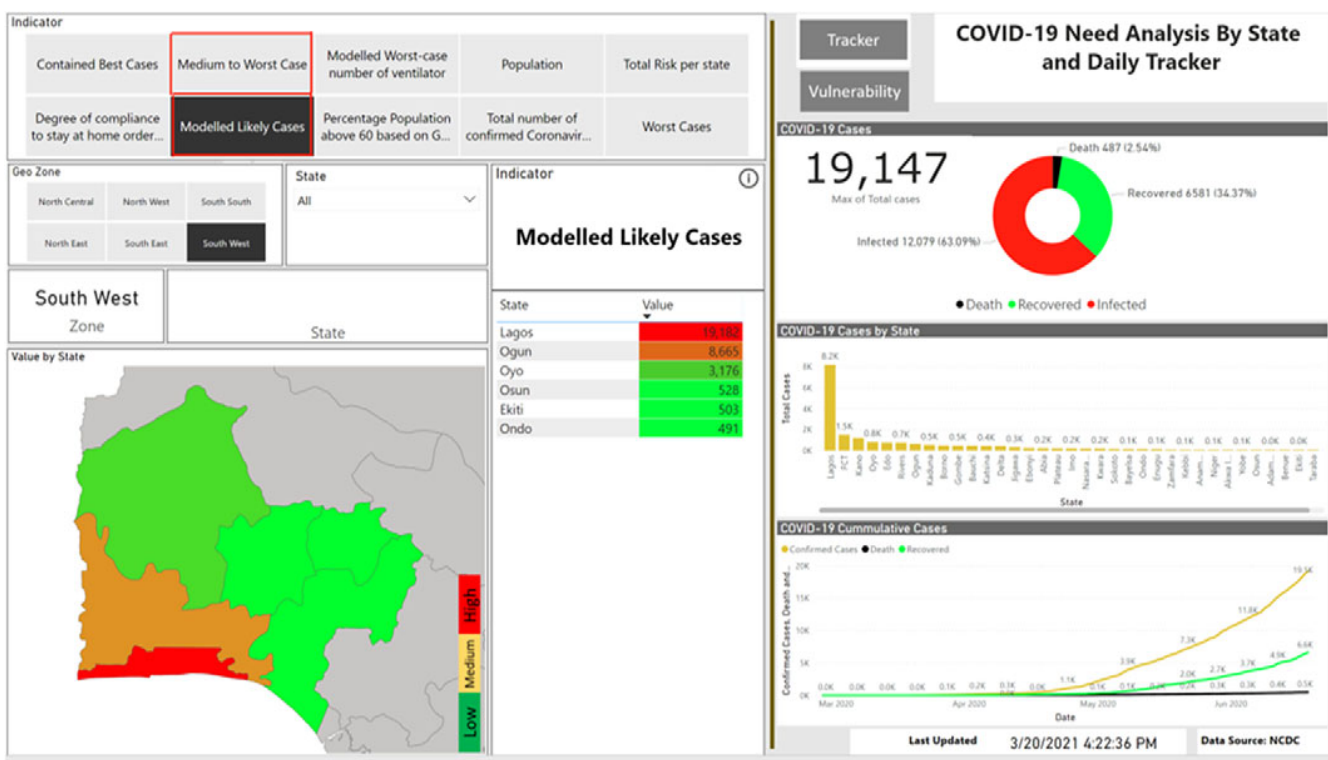

Figure 2. MTN dashboard: needs analysis by state with options including likely and worst-case scenarios.

\section{State COVID 19 Risk and Medical Need Assessment}

\begin{tabular}{|c|c|c|c|}
\hline \multicolumn{3}{|l|}{ State } & State \\
\hline \multicolumn{3}{|c|}{ Contained Best case } & 984 \\
\hline \multicolumn{3}{|c|}{ Worst Case } & 24,590 \\
\hline \multicolumn{4}{|c|}{ Medical Requirements } \\
\hline \multicolumn{3}{|c|}{ Gloves, examination $\times 1000$} & 5,087 \\
\hline \multicolumn{3}{|c|}{ Gloves, surgical, length to forearm large (Ionger than examination gloves) $\times 1000$} & 694 \\
\hline \multicolumn{3}{|c|}{ Face shield $\times 1000$} & 509 \\
\hline \multicolumn{3}{|c|}{ Particulate respirator, grade $\mathrm{N} 95$ or higher $\times 1000$} & 509 \\
\hline \multicolumn{3}{|c|}{ Mask, surgical $\times 1000$} & 347 \\
\hline \multicolumn{3}{|c|}{ Scrubs, tops $\times 1000$} & 509 \\
\hline \multicolumn{3}{|c|}{ Scrubs, pants $\times 1000$} & 509 \\
\hline \multicolumn{3}{|c|}{ Apron, heavy $\times 1000$} & 509 \\
\hline \multicolumn{3}{|c|}{ Gown $\times 1000$} & 509 \\
\hline \multicolumn{3}{|c|}{ Shoe covers $\times 1000$} & 509 \\
\hline \multicolumn{3}{|c|}{ Buffon Caps $\times 1000$} & 509 \\
\hline \multicolumn{3}{|c|}{ Goggles, protective $\times 1000$} & 509 \\
\hline \multicolumn{3}{|c|}{ Alcohol-based hand rub X1000 } & 5,087 \\
\hline \multicolumn{3}{|c|}{ Soap (liquid, powder and bar) $\times 100 \mathrm{ml}$} & 54,341 \\
\hline \multicolumn{3}{|c|}{ Hand drying tissue $\times 1000$} & 231 \\
\hline \multicolumn{3}{|c|}{ Biosafety Cabinet, Installation and Certification Cost } & 1 \\
\hline \multicolumn{3}{|c|}{ COPAN Universal(Virus) Transport Medium (UTM and Swab) } & 5 \\
\hline \multicolumn{3}{|c|}{ Cooling for GeneXpert to function optimally $1 \mathrm{Hp}$ Westpoint + Installation } & 1 \\
\hline \multicolumn{3}{|c|}{ Solar Power and Batteries that can support AC } & 20 \\
\hline \multicolumn{3}{|c|}{ Instalation and ancillary services } & 1 \\
\hline \multicolumn{3}{|c|}{ GeneXpert Cartridges } & 5,781 \\
\hline \multicolumn{3}{|c|}{ Beds for treatment } & 162 \\
\hline \multicolumn{3}{|c|}{ HR - Management of COVID 19 (DoctorsilNursesiCHEWS] } & 9,348 \\
\hline \multicolumn{3}{|c|}{ Oxygen cylinders (units) } & 173 \\
\hline \multicolumn{3}{|c|}{ Oxygen concentrators (units) } & 58 \\
\hline \multicolumn{3}{|c|}{ Flow splitter (Oxygen concentrator) X1000 } & 58 \\
\hline Oxygen & lasal, non-sterile, single use ( $\times 1000)$ & & 58 \\
\hline Oxygen & $000)$ & & 58 \\
\hline Oxygen t & nsion $(\times 1000)$ & & 58 \\
\hline $4 \quad+$ & X State Requirements & WHO Stanc & nent \\
\hline
\end{tabular}

Figure 3. Example of medical requirement for each scenario by state. 


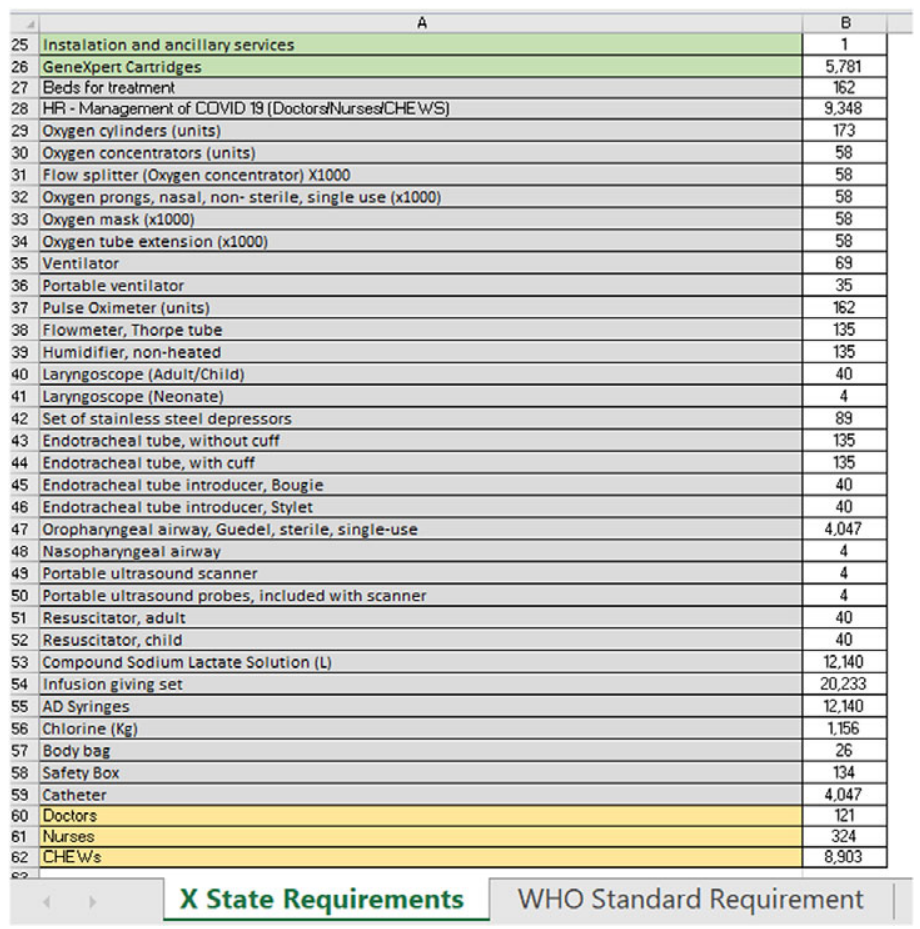

Figure 4. Example of medical requirement for each scenario by state (continued).

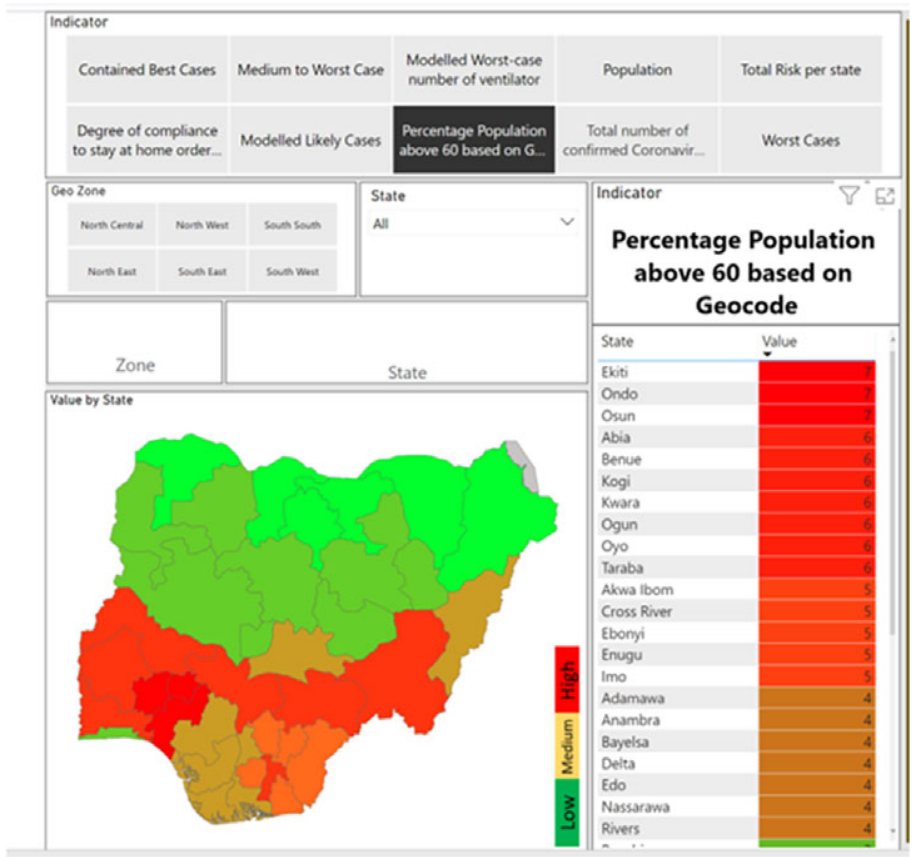

Figure 5. The MTN dashboard. In this example, indicating the percentage of the population over 60 years old by state. 


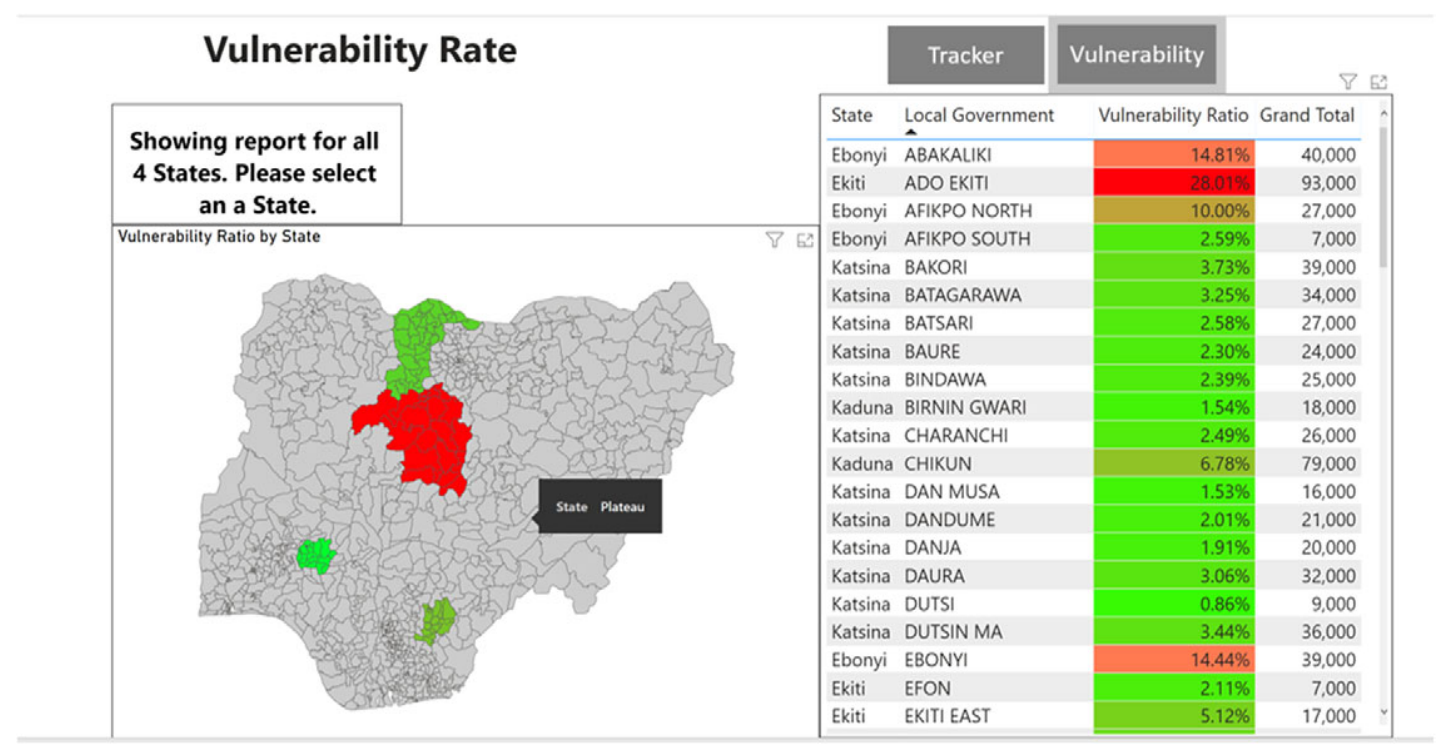

Figure 6. The MTN dashboard. In this example, showing vulnerability ratio by state.

Table 1. Stakeholder roles

\begin{tabular}{ll}
\hline Stakeholder & Role \\
\hline MTN & $\begin{array}{c}\text { Provision of the anonymised dataset, platform for } \\
\text { analysis, hosting external dataset that was merged } \\
\text { with internal data and deployment of its in-house } \\
\text { data scientists } \\
\text { Mobilization of other stakeholders for the } \\
\text { intervention support/fund raising to support the } \\
\text { vulnerable segment }\end{array}$ \\
$\begin{array}{ll}\text { Provision of additional database of physically } \\
\text { challenged people and the elderly }\end{array}$ \\
$\begin{array}{l}\text { Endorsement and mobilization of support } \\
\text { Development and provision of the payment and } \\
\text { disbursement platform }\end{array}$ \\
Softcom Eyowo (a brand of Softcom) & $\begin{array}{c}\text { Accountable tracking of the fund disbursement to the } \\
\text { vulnerable group }\end{array}$ \\
Deloitte & $\begin{array}{l}\text { Legal support } \\
\text { Platform assurance }\end{array}$ \\
Banwo Igbodalo and Co & $\begin{array}{l}\text { Mobile money distribution agency } \\
\text { EY }\end{array}$ \\
SANEF & Business and support services \\
GTBank, Providus Bank, Future Africa, Qrios, & \\
Bank of Industry, John Ashley, and & \\
Wilddreams &
\end{tabular}

MTN enriched the vulnerability population cluster insights with a cross industry database of sociodemographic segmentation groupings, incorporating data from, Lagos State; World Bank Data on the poorest households; LASRRA Data on aged Lagosians; Lagos State Residents for those living with disabilities; Bank of Industry Data on Market Women. This data was made available for use by Lagos State government. 
People and families located in the vulnerable areas are encouraged to apply for grants through the HelpNow initiative. With consent from the applicants, Softcom and Eyowo verify the eligibility of the application. Once applications are approved, 5,000 Naira is transferred directly to each beneficiary's bank account or phone number. Donations are disbursed every hour between 8 am and 6 pm daily to selected beneficiaries on the queue based on the vulnerability scoring. While the distribution was done generally, the areas identified with highest concentration of the most vulnerable population received direct on-site intervention by the Lagos State Emergency Food Response Initiative (Sadekoge, 2020).

The initiative has identified 2 million people in the vulnerable classification in Lagos State. To October 20, 2020, approximately 12 million Nigerian Naira (c32,000 USD, 24,500 GBP), had been distributed to 2,423 beneficiaries across 20 local government areas in Lagos State (Figures 7-9 and Table 2).

丹13,141,555

TOTAL DONATIONS

431

DONORS
N13,141,555

CASH DONATIONS
N12,115,000

CASH DISBURSED

Figure 7. HelpNow donations and disbursements (Homepage HelpNow, n.d.).
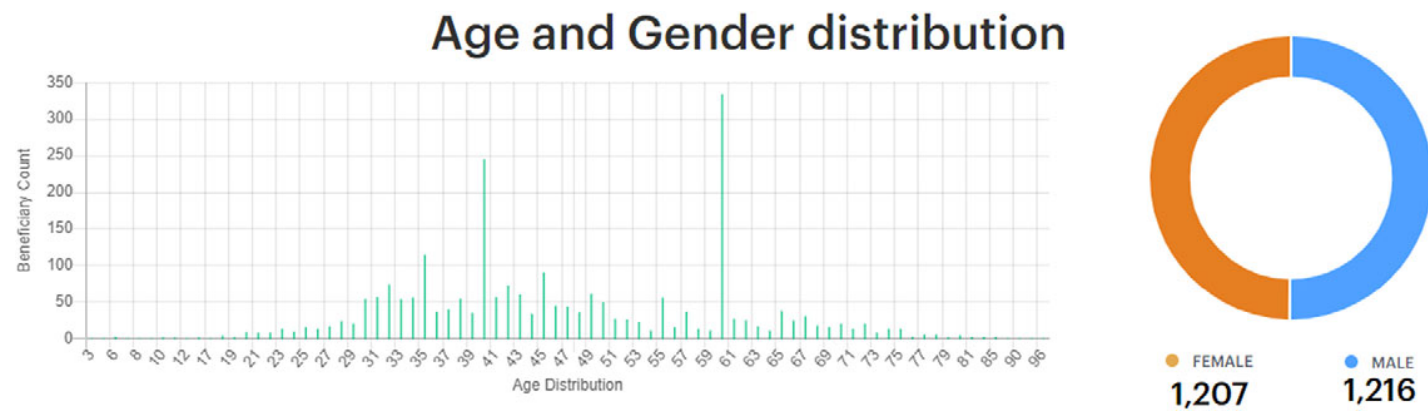

Figure 8. HelpNow donations by age and gender distribution Homepage (HelpNow, n.d.).

\section{Disbursements by LGA}

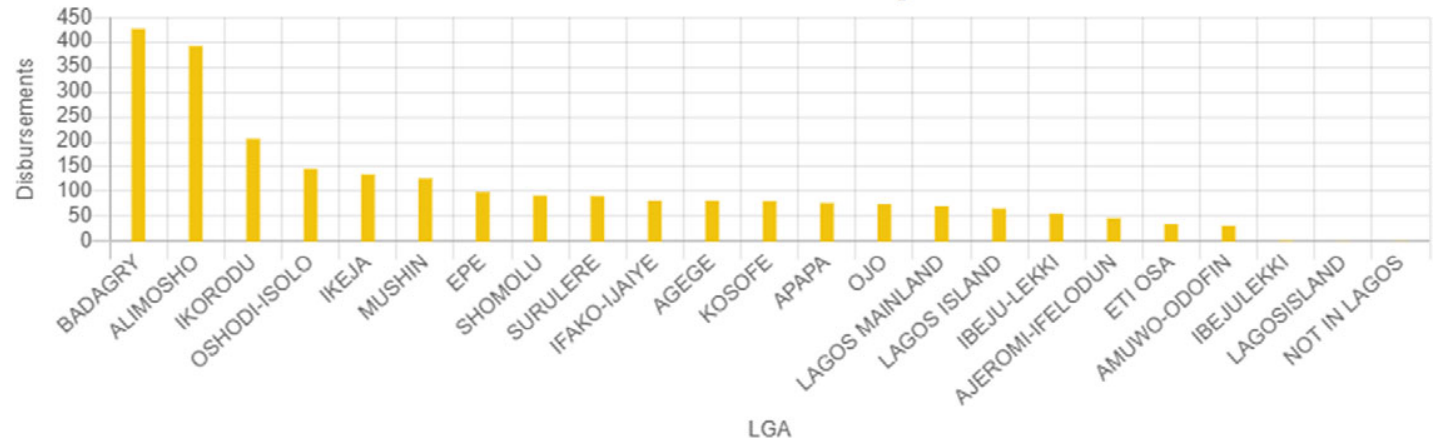

Figure 9. Disbursements by local government Area (HelpNow, n.d.). Source: Homepage HelpNow (n.d.). 
Table 2. Open-source data sources and epidemiological modeling references

\begin{tabular}{|c|c|c|}
\hline $\begin{array}{l}\text { Geospatial reference } \\
\text { datasets }\end{array}$ & GeoPoDe & https://geopode.world/ \\
\hline $\begin{array}{l}\text { Georeferenced } \\
\text { infrastructure and } \\
\text { demographic data } \\
\text { for development }\end{array}$ & GRID3 & https://grid3.gov.ng/ \\
\hline \multirow[t]{3}{*}{$\begin{array}{l}\text { Infectious disease } \\
\text { modeling }\end{array}$} & Lancet model 1 & $\begin{array}{l}\text { https://www.thelancet.com/journals/laninf/article/PIIS1473- } \\
\text { 3099(20)30243-7/fulltext }\end{array}$ \\
\hline & Lancet model 2 & $\begin{array}{l}\text { https://www.thelancet.com/journals/laninf/article/PIIS1473- } \\
\text { 3099(20)30144-4/fulltext }\end{array}$ \\
\hline & $\begin{array}{l}\text { COVID spread } \\
\text { model }\end{array}$ & $\begin{array}{l}\text { https://www.researchgate.net/publication/340114074_ } \\
\text { Mathematical_modeling_of_the_spread_of_the_- } \\
\text { coronavirus_disease_2019_COVID-19_taking_into_- } \\
\text { account_the_undetected_infections_The_case_of_China }\end{array}$ \\
\hline
\end{tabular}

\section{Conclusion}

With the arrival of the COVID-19 pandemic in 2020, a collaboration between the NGF and MTN Nigeria enabled data-driven insights to shape the planning and response to the disease.

In the first phase, the project developed a model to predict the worst-case scenario for infections in each state. This was used to support the health committees with local resource planning decisions. This predictive analysis was possible due to anonymized and aggregated mobile network data being combined with geospatial reference datasets from open-source public data repositories and applied to an epidemiological model. MTN presented the National Needs Analysis and Resource Requirement Dashboard centrally and from there the data were cascaded to all of the commissioners of health across the 36 states.

The second phase focused on understanding where the population at greatest socioeconomic risk from the impact of the disease were clustered geographically. Containment interventions, which were designed to reduce population movement and interaction to halt transmission, meant many subsistence/daily paid workers lost their source of income and ability to buy essential food supplies. When many of the wealthier members of society stepped in to help their neighbors survive, those populations located outside of the community response activities could not access the vital support. MTN were able to identify the geographies with the most vulnerable population through the application of (anonymized and aggregated) mobile money transactions, as proxy indicator for economic status, validated by third-party economic indicators and layered with infrastructure insights from geospatial reference datasets.

This insight went on to form the basis for the geographical targeting for the HelpNow crowdfunding platform which at the end of October 2020, had distributed critical financial support to 2,423 economically vulnerable beneficiaries across Lagos state.

This activity was rapidly developed and accelerated in response to a major national crisis, and as such did not define impact objectives or measurable outcome criteria.

\subsection{Initial lessons learnt}

\subsubsection{Regulatory support is critical to success}

This was not the first experience of working with CDR data for MTN Nigeria. The in-house capacity existed to anonymize and aggregate the CDR data, combine it with third-party data and undertake MBD analytics to generate unique insights, before the COVID-19 project commenced. Previous projects, however, were limited to small geographical areas and short time periods with an academic focus. 
A key factor in the success, and significant increase in scale, for this project was the support and guidance from the regulatory body, the NCC. Following the government request for insights, MTN began to discuss the approach, and particularly the approach to data privacy, with the NCC. The GSMA COVID-19 Data Privacy Guidelines (GSMA, 2020) and the Nigeria Data Protection Regulation were used as a starting point for discussion, and the NCC not only approved but also supported the entire process as everyone rose to reduce the negative impact of COVID-19. This enabled MTN to deliver insights at a national level (population 195 million), using data from a 3-4-month time period to support the COVID-19 response.

It was recognized, that there are a number of key areas to consider with regard to privacy, including adherence to the existing local laws, policies such as Nigerian Data Protection Regulation and General Data Protection Regulation where relevant, and also guidelines such as the GSMA COVID-19 Data Privacy Guidelines.

\subsubsection{Project delivering for impact and social good requires strong stakeholder engagement}

This was not a technically led delivery project but instead a strategic stakeholder engagement activity "for impact." Close engagement with core stakeholders, such as NGF and NCC was critical to this process. It required executive level management from MTN to provide guidance on the boundaries of intervention.

The multilevel governance structures in place, through the NGF, required a dedicated coordination activity to ensure that the multiple meetings, required to disseminate important findings, took place with the appropriate audience.

Time and effort was required to ensure the decision makers could interpret insight to inform decisions on the ground. This project demonstrated that, even within one country, the governance structure can differ-in this case by state - which required a different model of engagement between the insight creators and the decision makers. MTN took time and care, and ensured the appropriate level of senior engagement, to help the recipients of the insights, within the states, understand deeply enough to inform decision-making.

\subsubsection{Preparedness through ecosystem relationships}

Existing relationships were a critical factor in the delivery of the project, and this was particularly the case with the private sector "Help Now" initiative. It is only possible to leverage relationships that have already been built and MTN had previous experience of building solutions across the Nigerian innovation ecosystem, with academic institutions, and with development agencies. These existing partnerships provided an easy environment to deliver COVID-19 specific innovations and data integration.

\subsubsection{A foundation for the future}

Through this process, MTN were able to demonstrate to the NGF and NCC just how MBD can contribute unique insights and support planning and decision making. As the situation evolved from a health crisis to an economic crisis, the team were able to flex and evolve to provide relevant insights for new questions. This has established an understanding that MBD can be applied to many different use cases.

Anticipating the need to support future use cases, MTN are now setting up a dedicated team: AI for Social Good. Situated within the organization, this team will work toward ensuring future preparedness with an aim of supporting national interventions in response to natural disasters and epidemics.

Acknowledgment. The authors are grateful for the support provided by Mojca Cargo, Juliet Maina, and Jade Nester.

Funding Statement. This preparation of the manuscript was supported by grants from the UK Foreign Commonwealth and Development Office. The funder had no role in study design, data collection and analysis, decision to publish, or preparation of the manuscript.

Competing Interests. The authors declare no competing interests exist.

Author Contributions. Writing - original draft, J.G.; Reviewing and editing, O.A. and C.H; Final draft approval, J.G., O.A., and C.H.

Data Availability Statement. Data availability is not applicable to this article as no new data were created or analyzed in this study.

Supplementary Materials. To view supplementary material for this article, please visit http://dx.doi.org/10.1017/dap.2021.12. 


\section{References}

Akinwotu E (2020) ‘We Needed to Do More’: Volunteers Step Up in Lockdown Lagos. [Online]. The Guardian. Available at https:// www.theguardian.com/global-development/2020/may/02/we-needed-to-do-more-volunteers-step-up-in-lockdown-lagos (accessed 28 October 2020).

Ayoade $O$ (2020) The Economic Repercussion of Coronavirus Pandemic on Nigerians. Available at https://pulitzercenter.org/ reporting/economic-repercussion-coronavirus-pandemic-nigerians (accessed 25 September 2020).

Bayagbon O (2020) Hunger in the Land: How the Poor are 'Knocking on the Gates' of the Rich During Lockdown | The cable. [Online]. The Cable. Available at https://www.thecable.ng/hunger-in-the-land-how-the-poor-are-knocking-on-the-gates-of-therich-during-lockdown/amp (accessed 28 October 2020).

Biodun F (2020) MTN Supports Nigeria's Fight Against COVID-19 with Over N1.4b, Others. [Online]. Biztech Africa. Available at https://www.biztechafrica.com/article/mtn-supports-nigerias-fight-against-covid-19-over-/15615/ (accessed 19 May 2021 ).

Chirkpi L (2020) State Governors in Move with NCC, MTN to Deploy Consumer Data to Fight Covid-19 - Order Paper. [Online]. Order Paper. Available at https://www.orderpaper.ng/state-governors-in-move-with-ncc-mtn-to-deploy-consumer-data-to-fightcovid-19/ (Accessed 28 October 2020).

Chitungo I, Dzobo M, Hlongwa M and Dzinamarira T (2020) COVID-19: Unpacking the Low Number of Cases in Africa. Public Health in Practice, September 11. Available at https://www.sciencedirect.com/science/article/pii/S2666535220300379.

Deloitte (2020) Understanding the Sector Impact of COVID-19 Oil \& Gas. Available at https://www2.deloitte.com/ng/en/pages/ finance/articles/understanding-the-sector-impact-of-covid-19-oil-and-gas.html (accessed 25 September 2020).

Dowd JB, Andriano L, Brazel DM, Rotondi V, Block P, Ding Z, Liu Y and Mills MC (2020) Demographic science aids in understanding the spread and fatality rates of COVID-19. Proceedings of the National Academy of Sciences 117(18), 9696-9698. https://doi.org/10.1073/pnas.2004911117

Essien U (2020) Governors, MTN Partner to Use Data to Halt Spread of COVID-19. [Online]. Nggovernorsforum.org. Available at https:/nggovernorsforum.org/index.php/73-featured-news/1564-governors-mtn-partner-to-use-data-to-halt-spread-of-covid19 (accessed 1 November 2020).

Geopode.world (2020) Geopode [Online]. Available at https://geopode.world (accessed 28 October 2020).

Grid3.gov.ng (2020) Welcome - GRID3. [Online]. Available at https://grid3.gov.ng/about (accessed 28 October 2020).

GSMA (2020) The GSMA COVID-19 Privacy Guidelines. Available at https://www.gsma.com/publicpolicy/wp-content/uploads/ 2020/04/The-GSMA-COVID-19-Privacy-Guidelines.pdf (accessed 25 September 2020).

GSMA Intelligence (2020) Sub-Saharan Africa, Q1 2020 Covid-19: A Mixed Impact for the Digital Ecosystem. Available at https:// data.gsmaintelligence.com/api-web/v2/research-file-download?id=54165556\&file=110620-RIF-SSA-Q120.pdf (accessed 25 September 2020).

HelpNow (n.d.) Homepage HelpNow. [Online]. Available at https://helpnow.ng (accessed 21 May 2021).

Kucharski A, Russell T, Diamond C, Liu Y, Edmunds J, Funk S, Eggo R, Sun F, Jit M, Munday J, Davies N, Gimma A, van Zandvoort K, Gibbs H, Hellewell J, Jarvis C, Clifford S, Quilty B, Bosse N, Abbott S, Klepac P and Flasche S (2020) Early dynamics of transmission and control of COVID-19: A mathematical modelling study. The Lancet Infectious Diseases 20(5), 553-558.

MTN Online (2021) Y'ello Hope-MTN Online. [Online]. Available at https:/www.mtnonline.com/covid-19/yello-hope/ (accessed 19 May 2021).

Nigerian Communications Commission (2020) Industry Statistics [Online]. Available at https://www.ncc.gov.ng/statisticsreports/industry-overview\#view-graphs-tables-2 (accessed 28 October 2020).

Nigerianstat.gov.ng (2020) [Online]. Available at https://www.nigerianstat.gov.ng/pdfuploads/Telecoms_Sector_Data_-_Q1_ 2020.pdf (accessed 30 October 2020).

Nwachukwu I (2020) Oando Says Over 21,000 Lagosians to Benefit from its Employees' Food Relief Initiative-Businessday NG. [Online]. Businessday NG. Available at https://businessday.ng/news/article/oando-says-over-21000-lagosians-to-benefitfrom-its-employees-food-relief-initiative/ (accessed 28 October 2020).

Omondi J (2020) Nigeria Extends Second Phase Nationwide COVID-19 Lockdown by Four Weeks. Available at https://africa.cgtn.com/ 2020/08/06/nigeria-extends-second-phase-nationwide-covid-19-lockdown-by-four-weeks/ (accessed 25 September 2020).

Onder G, Rezza G and Brusaferro S (2020) Case-fatality rate and characteristics of patients dying in relation to COVID-19 in Italy. JAMA 323(18), 1775-1776. http://dx.doi.org/10.1001/jama.2020.4683

Partners N (2020) COVID-19: Oando Employees Raise Over N25 Million, Feed 10 Communities Across Lagos. [Online]. Nairametrics. Available at https://nairametrics.com/2020/05/22/covid-19-oando-employees-raise-over-n25-million-feed-10communities-across-lagos/ (accessed 28 October 2020).

Sadekoge (2020) Covid-19: The Lagos State Emergency Food Response Initiative - Lagos State Government. [Online]. Lagos State Government. Available at https://lagosstate.gov.ng/blog/2020/04/14/covid-19-the-lagos-state-emergency-food-response-initia tive/ (accessed 20 May 2021).

The World Bank (2020) Monitoring COVID-19 impact on Nigerian households. Available at https://www.worldbank.org/en/ country/nigeria/brief/monitoring-covid-19-impact-on-nigerian-households (accessed 25 September 2020).

Cite this article: Gilbert J, Adekanmbi $O$ and Harrison C (2021). Using mobile big data to support emergency preparedness and address economically vulnerable communities during the COVID-19 pandemic in Nigeria. Data \& Policy, 3: e21. doi:10.1017/ dap. 2021.12 